\title{
Impacts of land use and invasive species on native avifauna of Mo'orea, French Polynesia
}

\author{
Vanessa M ZoBell corresp., 1, 2, Brett J Furnas ${ }^{2,3}$ \\ 1 Department of Wildlife, Fish, and Conservation Biology, University of California, Davis, Davis, California, United States of America \\ 2 Department of Environmental Science, Policy, and Management, University of California, Berkeley, Berkeley, California, United States of America \\ 3 Wildlife Investigation Laboratory, California Department of Fish and Wildlife, Rancho Cordova, California, United States of America \\ Corresponding Author: Vanessa M ZoBell \\ Email address: vmzobell@ucdavis.edu
}

Oceanic islands are among the most endemically biodiverse ecosystems in the world. They have been adversely impacted by human expansion, which affects regional biodiversity by altering the natural habitats of vulnerable, indigenous species. Birds represent a valuable indicator species of environmental change due to their ability to adapt quickly. Investigating the relationship between environmental change, abundance, and behaviors of birds can help us better anticipate potential impacts to island ecosystems. In addition, we can understand the population trends and restricted ranges of native avifauna, identify the regions needing protection, and assess habitat vulnerability linked to anthropogenic activities. In Mo'orea, French Polynesia, we studied nine passerine bird species using automated acoustic recording devices placed in agricultural, forested, and mixed habitats. Based on call counts per unit time and occupancy modeling, we found evidence that three non-native species preferred agricultural areas and low-canopy cover over dense forested areas. Furthermore, native bird detectability and possibly abundance was significantly lower than non-native birds. Using hierarchical cluster analysis to support inferences regarding behavioral differences, we found that native bird calling activity was negatively associated with non-native bird calling activity. Altogether, these results suggest native bird populations are at risk in all of the habitats studied, but forests serve as a potential refuge. 
1 Impacts of Land Use and Invasive Species on Native Avifauna of Mo'orea, French Polynesia

2 Vanessa M ZoBell

3 Department of Wildlife, Fish, and Conservation Biology, University of California, Davis, Davis,

4 California, United States of America

5 Department of Environmental Science, Policy, and Management, University of California,

6 Berkeley, Berkeley, California, United States of America

7 Brett J Furnas

8 Wildlife Investigations Laboratory, California Department of Fish and Wildlife, Rancho

9 Cordova, California, United States of America

10 Department of Environmental Science, Policy, and Management, University of California,

11 Berkeley, Berkeley, California, United States of America 
12 Abstract.

13 Oceanic islands are among the most endemically biodiverse ecosystems in the world. They have

14 been adversely impacted by human expansion, which affects regional biodiversity by altering the natural habitats of vulnerable, indigenous species. Birds represent a valuable indicator species of environmental change due to their ability to adapt quickly. Investigating the relationship between environmental change, abundance, and behaviors of birds can help us better anticipate potential impacts to island ecosystems. In addition, we can understand the population trends and restricted ranges of native avifauna, identify the regions needing protection, and assess habitat vulnerability linked to anthropogenic activities. In Mo'orea, French Polynesia, we studied nine passerine bird species using automated acoustic recording devices placed in agricultural, forested, and mixed habitats. Based on call counts per unit time and occupancy modeling, we found evidence that three non-native species preferred agricultural areas and low-canopy cover over dense forested areas. Furthermore, native bird detectability and possibly abundance was significantly lower than non-native birds. Using hierarchical cluster analysis to support inferences regarding behavioral differences, we found that native bird calling activity was negatively associated with non-native bird calling activity. Altogether, these results suggest native bird populations are at risk in all of the habitats studied, but forests serve as a potential refuge.

\section{Introduction.}

Biodiversity is impacted negatively by human-caused alterations of natural habitats through industrialization, agriculture, logging, and commercial and residential development (Florens et al., 2012; McKinney, 2002; Repetto,1988). The reduction in floristic and structural diversity caused by agriculture can result in decreased habitat for many animals that rely on natural ecosystems (Stoate et al., 2009). Agriculture practices specifically impact birds by altering and eliminating their habitat, nesting availability, and food sources (Bunce et al., 1998; Vickery et al., 2001). For example, the use of fertilizer is known to alter bird occurrence by changing the amount and composition of soil-dwelling invertebrates for consumption (Scullion \& Ramshaw, 1987; Tucker, 1992; Vickery et al., 2001). Livestock grazing can also alter biodiversity by removing plants needed for nesting and shelter (McLaughlin \& Mineau, 1995). Non-native species may reduce biodiversity by encroaching and thriving on new, human-altered habitats such as agricultural areas, and outcompeting their native counterparts for resources (Mack et al., 2000; Gurevitch \& Padilla, 2004).

Oceanic islands are among the most endemically biodiverse in the world because of their isolation. It is their endemism that makes them vulnerable to anthropogenic disturbances (Paulay, 1994). French Polynesian oceanic islands host many native and endemic species from molluscs (Partula mooreana) and plants (Nesoluma nadeaudii) to avifauna (Ptilinopus purpuratus) (Clarke et al., 1984; Meyer \& Butaud, 2009; Wray, 2013). On French Polynesian islands, the need for human resources has led to more agriculture areas in recent years (Kennett et al., 2006). When humans colonized French Polynesia in the early Holocene years, they introduced new animals and plants, and altered the land so it could support their population's needs (Ferdon, 1981; Whistler, 1991). Agricultural intensity increased after the arrival of Europeans who introduced pesticides and other agrochemicals (Bovis, 1976; Sakagawa, 1993). 
57 Birds play a critical role in conservation, acting as "indicator" species as they adapt quickly to environmental change demonstrating how other species may change in the future (Briggs et al., 2013). By dispersing seeds, they keep the forests rich with plant growth and link habitats that would otherwise remain unconnected (Galindo-Gonzalez et al., 2000; Didham et al., 2005). Birdrelated seed dispersal plays a major role in the genetic exchange in plant populations as well. Should they disappear, birds would not perform ecosystem services, causing detriment to the habitats they live in (Galindo-Ganzalez et al., 2000; Didham et al., 2005; Briggs et al., 2013). Therefore, surveying birds to monitor changes in their distribution and population will help researchers identify impact on the larger ecosystem (Briggs et al., 2013).

Despite agricultural conversion of native forests on the island of Mo'orea in French Polynesia, little research has been conducted on the distribution of native and non-native avian fauna on this island. Though the Opunohu Valley on Mo'orea was identified as an Important Bird Area (IBM) by Birdlife International in 2006, a threat score, condition score, and action score have not yet been assessed for the valley (BirdLife International, 2017). Therefore, the objective of the present study was to survey nine passerine bird species across forested and agricultural habitats within the Opunohu Valley using automated acoustic recording units. Two of the nine passerine birds, the grey-green fruit dove and the Mo'orean kingfisher, are native (Wray, 2013), and Mo'orean kingfisher is an endemic to Mo'orea (Wray, 2013). Automated acoustic recording units are a valuable technology to help survey a wide variety of avian species concurrently (Haselmayer \& Quinn, 2000; Hobson et al., 2002; Rempel et al., 2005; Brandes, 2008; Furnas \& Callas, 2015).

Based on the survey, we evaluate differences in activity and occupancy among native and nonnative species, attempt to assess their vulnerabilities to agriculture and loss of forest habitat, and also make recommendations for expanding avian monitoring throughout Mo'orea.

\section{Methods.}

\section{Study area}

We conducted this research on the island of Moorea, a high volcanic island, $134 \mathrm{~km}^{2}$ in size, in the Society Islands of French Polynesia (Fig 1, 2), where human settlement occurred heavily along the coast of the island as well as in flat river valleys. However, much of the island's rugged interior is unsettled and covered in dense forest filled with Tahitian chestnut (Inocarput fagifer), hibiscus (Hibiscus rosa-sinensis), miconia (Miconia calvescens), and candlenut (Aleurites moluccana). Our bird surveys were limited to the Opunohu Valley, a fertile river valley of diverse land use, from intensive agriculture to protected forests, both interspersed among mixed-used areas. Much of the Opunohu Valley floor currently provides livestock grazing whereas the remnant lowland valley forests are dominated by dense vegetation, some of which is non-native (Lepofsky et al., 1996). Farming is intermixed within the Opunohu Valley in multiple areas (HOW MANY AREAS).

\section{Study Species}

The native birds we targeted for acoustic surveys are grey-green fruit dove (Ptilinopus purpuratus) and Mo'orean kingfisher (Todiramphus veneratus). The introduced, resident avifauna species we surveyed are red jungle fowl (Gallus gallus), zebra dove (Geopelia striata), red-vented bulbul (Pycnonotus cafer), common myna (Acridotheres tristis), silvereye (Zosterops 
103 lateralis), common waxbill (Estrilda astrild), and red-browed firetail (Neochmia temporalis).

104 Together, these nine species represent all of the terrestrial passerine avifauna on Mo'orea,

105 excluding chestnut-breasted mannikin (Lonchura castaneothorax) (Wray, 2013). We were not

106 able to distinguish Chestnut-breasted mannikin (Lonchura castaneothorax), a terrestrial resident

107 passerine, from spectrogram displays, or find evidence of it being in the agricultural or forested

108 areas so it was not included in this study. Additionally, the Tahiti swiftlet (Aerodramus

109 leucophaeus) has not been seen on Mo'orea since 1973 (Marshall Cavendish Corporation, 2001).

110 We did not verify the presence of this species during monitoring so it was also excluded in this

111 study. We did not include seabirds or shorebirds in our study because they were rarely

112 encountered at the sites we sampled in the Opunohu Valley.

113

114 Selection of field sites

115 To assess the impact of human land use on the bird community, we first stratified the study area

116 by land-use types (forested, agricultural, or mixed) based on visual inspection of satellite

117 imagery (Google Earth). We overlaid a grid consisting of $267 \mathrm{~m}$ wide quadrats and assigned each

118 to one of the three strata. Second, we randomly selected five quadrats within each of the three

119 land use types (15 sites total, Fig 1). We constrained randomization so that each study site was

120 located $>250 \mathrm{~m}$ apart to ensure double counting did not occur (Bibby et al., 2000). We examined

121 each site in person before sampling to ensure that the habitat type was identified correctly from

122 the satellite imagery.

123

124

125

126

127

128

129

130

131

132

133

Ideally, we established a survey site at the center of a selected quadrat. If this point was not accessible, a random distance and bearing was chosen to offset the location. We recorded canopy cover by using five descriptive canopy cover types: open, open/moderate, moderate, moderate/covered, and covered. Canopy cover was defined by visually assessing the percent of canopy covered by vegetation within an approximately 10 meter by 10 meter box. $0 \%$ coverage defined open canopy, 25\% coverage defined open/moderate canopy, 50\% coverage defined moderate canopy, $75 \%$ coverage defined moderate/covered canopy, and 100\% coverage defined covered canopy.

\section{Acoustic sampling}

134 We deployed an automated acoustic recording unit [Olympus DM-620s (Olympus Corporation,

135 Center Valley, PA) or Songmeter4 (Wildlife Acoustics Inc., Concorde, MA, USA)] to record

136 bird vocalizations at each survey site. We rotated use of the two models of recording devices so

137 that an equal number of samples from each model were made in each habitat stratum. This

138 helped us mitigate any issues pertaining to an expected difference in effective sampling area of

139 the two models. The detection range of the acoustic recorders was not measured in our study.

140 However, after attempting visual surveys, we discovered that acoustic recorders in all forested

141 areas and many mixed areas were able to receive calls from birds that were visually obstructed

142 from extremely dense vegetation. For less dense forested habitats in California, Furnas and

143 Callas (2015) determined an effective acoustic range of approximately $50 \mathrm{~m}$ for the Olympus

144 recorders. It is likely that the detection range of the Wildlife Acoustics recorder is greater than

145 that of the Olympus.

146

147 Each automated recorder was placed on the ground within $5 \mathrm{~m}$ of the selected point in the

148 quadrat where reception of song was likely to be highest. Adjacent sites were not sampled on the 
149 same day to further reduce the chance of recording the same individual from two different sites.

150 In forested sites, we placed the recording device in the clearest area within the $5 \mathrm{~m}$ radius so

151 acoustic reception would not be altered by understory vegetation. Following the protocol of

152 Furnas and Callas (2015), we programmed the units to record for five minutes three times each

153 morning commencing at 30 minutes before local sunrise, sunrise, and 30 minutes after sunrise.

154 Surveys were repeated on three consecutive mornings totaling nine recordings summing to 45

155 minutes at each site. We chose this method to ensure that all species of birds were recorded,

156 taking into account that species may prefer different calling hours. The recordings from our 15

157 survey sites summed to 675 minutes from 45 site-morning combinations. The acoustic recorders

158 were set to record at a sample rate of $24 \mathrm{kHz}$ and a reception level minimum of $16.0 \mathrm{~dB}$ and a

159 maximum of $122 \mathrm{~dB}$. The bandwidth of the recording devices ranged from $20 \mathrm{~Hz}$ to $49 \mathrm{kHz}$.

160

161

162

163

Call validation and interpretation of survey recordings

164

To ensure accurate interpretation of our survey recordings, we first completed a pilot study to record reference bird calls for each species while visually confirming the species identities of the vocalizing birds. Multiple reference examples were made for each species to ensure variety in call types identified. We made spectrograms of the validated calls and used them to calibrate species identifications in spectrograms of the recordings from the field.

We extracted the acoustic data from our recording devices via a micro SD card and uploaded them to a computer. All acoustic recordings were converted into an adapted .wav file format for analysis. Analyses were conducted using the Triton processing software program (Wiggins \& Hildebrand, 2007), based in MATLAB (MathWorks Inc., Natick, MA), to calculate and display standard spectrograms, to perform audio playbacks, and to log call detections.

One trained acoustic analyst interpreted all of the recordings to minimize any bias that might occur with multiple analysts. The analyst excluded any detections in which she was unsure of the species identification. Less than 20 vocalizations were excluded. We excluded two out of the 45 site-mornings because of intense anthropogenic noise covering birdcalls in the spectrograms.

The analyst visually scanned spectrograms by examining a 10 second window with time and frequency resolutions bins of 5 seconds and $100 \mathrm{~Hz}$ respectively (1000 point FFT, 75\% overlap). Because of the differences in call structure, defining a single vocalization differed for each species as described below.

Red-vented bulbul calls are most commonly two or three toned, and range from frequencies of 1000 to $3000 \mathrm{hz}$. Red-vented bulbuls are less commonly found making single tone calls (Supplemental Information). Every every two-tone and three-tone call was considered unique (recorded as a new call) (Supplemental Information). A unique call could be from the same individual, or a new individual. Common waxbill darts are categorized by their high frequency and short duration. The darts range in frequency from 3000 to $8000 \mathrm{hz}$. The source level is low, and is sometimes, but not often, covered by the high source level of the silvereye call (Supplemental Information). Every dart was considered unique. Zebra dove, like grey-green fruit dove, show a call that contains a train of coos. The coos are faster and of shorter duration than the grey-green fruit dove. Zebra dove coos are also at a higher frequency than grey-green fruit

194 dove, at approximately 1000 to $15000 \mathrm{hz}$ (Supplemental Information). Zebra dove calls are 
195 considered unique every time a signature large coo occurs at the beginning of the "coo train."

196 The red jungle fowl call is a combination of sweeps and screeches, varying in frequency, and

197 most commonly found in between 1000 and $4000 \mathrm{hz}$ (Supplemental Information). Every screech

198 was considered a new call. The grey-green fruit dove "coo-train" is low frequency, and varied in

199 duration at approximately $400 \mathrm{hz}$ (Supplemental Information). The large "coo" at the beginning

200 of the grey-green fruit dove "coo train" determined the beginning a new call. The Mo'orean

201 kingfisher call is categorized as a shuddering "klew" that can vary greatly in duration. The

202 signature shudder of this call was was the largest identification factor. The frequency range of

203 the Mo'orean kingfisher call was very large, at times ranging from 10 to $4000 \mathrm{hz}$ in one call

204 (Supplemental Information). The Mo'orean kingfisher call was considered unique if there was a

205 two-second gap between the shuddering "klews." The common myna call was very complex, and

206 was comprised of different trills, screeches, downsweeps, and tonal calls. The common myna,

207 like the Mo'orean kingfisher, has a large range of frequency-calling abilities, and can range from

2081000 to $8000 \mathrm{hz}$ (Supplemental Information). The common myna call was considered new if

209 there was a one second gap between the calls. The red-browed firetail call is noted as a high

210 frequency upsweep trill. The upsweep is consistently most intense at a frequency of 6000 to 8000

$211 \mathrm{hz}$ (Supplemental Information). Each upsweep made was a new call. The downsweep of the

212 silvereye is most commonly found at a frequency of 3000 to $5000 \mathrm{hz}$ (Supplemental Information)

213 and its song is made up of an entanglement of downsweeps at this frequency. Every silvereye

214 downsweep was considered its own call, including all of the downsweeps making up the song.

215 Because of the wide variety of frequency, duration, and call structure in the different species'

216 calls, disentanglement of calls was not an issue in the spectrogram analyses.

217

218

219

220

221

222

223

224

225

226

227

228

229

230

Statistical Analyses

We used nested ANOVA to evaluate differences in call count per unit time in different habitats for each species. To this we tallied the number of calls heard per 5-minute survey by habitat and species. We tested if there were any significant differences in mean counts among the habitats by species.

We used hierarchical cluster analysis to further elucidate patterns of co-detection of bird species (Sharma, 1996; McCune et al., 2002). We limited this analysis to the subset of five sites at which all nine avian species were detected, a constraint which permitted inferences about temporal partitioning of vocal behavior among native versus non-native species. We used logistic regression to confirm temporal difference in species detections.

\section{Occupancy Modeling}

231 Occupancy modeling allowed us to differentiate our data on the species' calling frequencies into

232

233

234

235

236

237

238

239 separate processes governing the proportion of sites occupied by a species versus the detection probability of a species at an occupied site (MacKenzie et al., 2006). We used a multi-species modeling approach (Tingley et al., 2012; Iknayan et al., 2014) because of the small sample size. We had an insufficient sample size to include covariates on occupancy, but we did include canopy cover and whether a survey occurred before, during, or after sunrise as covariates on detection probability. We used the canopy cover covariate as a proxy representing the different land use types we surveyed (agricultural, mixed, and forest), because canopy cover was generally higher at forested and non-agricultural sites. We also used detection probability as an indicator of 
240

241

242

243

244

245

246

247

248

249

250

251

252

253

254

255

256

257

258

259

260

261

262

263

264

265

266

267

268

269

270

271

272

273

274

275

276

277

278

279

280

281

282

283

284

285

abundance, by reasoning that a species was more detectable at an occupied site because multiple vocalizing individuals were present (Royle \& Nichols, 2003).

Our model included fixed effects on species occupancy and hyperparameters on all detection probability parameters. Because we only surveyed focal species, we did not use data augmentation in the model. We fit a Bayesian model solved using a Markov Chain Monte Carlo (MCMC) algorithm (Link et al., 2002) implemented in JAGS (4.2.0, Plummer 2003) accessed via $R$ statistical software (3.3.1, www.r-project.org) with the jagsUI package (Kellner, 2015). Uninformative priors were assumed for all parameters. Three independent chains of 10,000 samples were run with a burn-in period of 5000 and a thinning rate of three. Effective mixing of these chains was assessed visually and by means of the Gelman-Rubin convergence statistic $(<1.1$;Gelman et al., 2004).

\section{Results.}

Results for Average Calling Number

The average number of calls per 5-minute survey was highest for two introduced species, silvereye and red-vented bulbul (Table 1). It was lowest for the two native species, Grey-green fruit dove and Mo'orean kingfisher. Common waxbill, zebra dove, and common myna all showed a significantly greater average call number per 5-minute survey in the agricultural sites $(\mathrm{p}<0.01)$ whereas red jungle fowl was significantly more prominent in forested areas $(\mathrm{p}<0.05)$ (Table 1). Red-vented bulbul, red jungle fowl, silvereye, red-browed firetail, Mo'orean kingfisher, and grey-green fruit dove showed no significant habitat association with the average number of calls data (Table 1). Zebra dove, common myna, and common waxbill showed a significant association with agricultural areas based on the number of total average calls at each site per 5 minutes (Table 1).

\section{Hierarchal Clustering Results}

We found strong evidence of temporal partitioning in the vocalizations of native versus nonnative species. In the assessment of 5-minute surveys, the hierarchical cluster analysis split detected species into two distinct groups that completely coincided with native versus non-native species (Fig 3). For Mo'orean kingfisher, logistic regression confirmed its detection during a survey was negatively associated $(\mathrm{p}=0.016)$ with the total number of non-native birds detected concurrently. On the other hand, there was no evidence of avoidance among the two native birds $(p=0.444)$

\section{Occupancy Modeling Results}

All but one of the species had occupancies $>0.8$, suggesting that these species were widespread throughout the study area (Fig 4). Only grey-green fruit dove, a native species, had an estimate occupancy of $<0.8$, but it was still $>0.6$.

Different morning times explained differences in detection probability among non-native species (Fig 5). All non-native species, except red-vented bulbul and red jungle fowl, displayed the same pattern whereby detection probability was higher after sunrise compared to before sunrise. In contrast, there was no discernable temporal pattern for the two native species; they did not call more or less at any of the morning times studied. 
286 We identified a negative relationship between canopy cover and detection probability for three

287

288

289

290

291

292

293

294

295

296

297

298

299

300

301

302

303

304

305

306

307

308

309

310

311

312

313

314

315

316

317

318

319

320

321

322

323

324

325

326

327

328

329

330

331 non-native species (common myna, common waxbill, and zebra dove), suggesting that these species may be more abundant in agricultural habitats (Fig 6). Four non-native species (redvented bulbul, red jungle fowl, silvereye, zebra dove) had the highest average detection probabilities per survey $(>0.5)$, whereas both native species (grey-green fruit dove and Mo'orean kingfisher) were among the group with the lowest detection probabilities $(<0.5)$ (Fig 5). Taken together, the occupancy modeling findings suggest that, although widely distributed, native species may occur at lower levels of local abundance than non-native species.

\section{Discussion.}

Acoustic Monitoring

Automated acoustic recording devices have been used in many different fields of biology to note acoustic activity of various species during different times of the year as well as different times of the day (Jones et al., 2013; Baumann-Pickering et al., 2015). These monitoring devices allowed us to efficiently repeat surveys at sites in remote areas that were difficult to access due to dense vegetation and steep inclines (Frommolt et al., 2008). However, visual point counts in addition to acoustic recordings could be conducted in Mo'orea to further improve the accuracy and precision of our surveys (Bibby et al., 2000). Both sources of data could be included in the same occupancy model (McGrann \& Furnas 2016).

\section{Inference about activity and abundance}

In this study, we found non-native birds calling at a significantly greater rate than native birds in each of the three habitats studied. Female and male avifauna in the tropics are known to call year-round; however, calling activity and call repertoire may change during breeding season (Montgomerie \& Weatherhead, 1988; NE Langmore, 1998). The breeding seasons of the native and non-native avifauna on Mo'orea vary from species to species or are unknown entirely (Spotswood, 2011). Future studies should analyze if and when the calling activity of Mo'orean avifauna changes throughout breeding seasons.

Furthermore, our use of occupancy modeling helped us make inferences about occupancy and abundance for native and non-native species. Survey-level detection probability was lowest for the two native species, grey-green fruit dove and Mo'orean kingfisher. This difference suggests that, while all bird species were widely distributed across all three land-use types (agricultural, forested, and mixed), local abundance of native species may have been lower than non-native species at occupied sites. On the other hand, detection probability of three non-native species (zebra dove, common myna, and common waxbill) was significantly higher in low canopy habitats, suggesting higher abundances in agricultural areas. This pattern may allow forested areas to provide a refuge for the native species because of reduced use of these are by nonnatives.

One caveat that must be considered when linking detection probability to inferences about abundance (Royle \& Nichols, 2003) is the sound transmission properties of different habitats. Lower detectability of three exotic species in higher canopy cover could be partially due to greater attenuation of calls in forested habitats (Catchpole \& Slater 2008). Low detectability of native birds due to sound attenuation, however, is unlikely. The call structure of native birds provides a greater likelihood of transmission because of the low frequency call of grey-green 
332 fruit dove and the high intensity, long duration call of Mo'orean kingfisher. Low frequency calls

333 are more likely to travel through forest habitats (Catchpole \& Slater, 2008), which may be a clue

334 to the evolutionary and behavioral adaptations of the native birds being adapted to live in a high-

335 density forest area. Therefore, lower detection probabilities of native versus exotic birds may be

336 evidence to reduced abundances for the former.

337

338

339

340

341

342

343

344

345

346

347

348

349

350

351

352

353

354

355

356

357

358

359

360

361

362

363

364

365

366

367

368

369

370

371

372

373

374

375

376

377

\section{Inferences about behavior}

The results of hierarchical cluster analysis and logistic regression showed that Mo'orean kingfisher calling behavior was negatively associated with the presence of non-native calls. Mo'orean kingfisher calls lie in the same frequency band as all of the non-native species' calls. Mo'orean kingfisher calls could be obfuscated by the vast number of calls from the non-native birds (as high as 40 per minute for red-vented bulbul). Mo'orean kingfisher may not be calling as frequently because their songs are not effectively transmitted in the presence of the non-native calls, or because there is a lower density of Mo'orean kingfisher altogether. The obfuscation of the Mo'orean kingfisher call may adversely affect their social behavior, reproductive success, and overall population numbers.

Native bird calls may be less obfuscated by non-natives in the early morning. As seen in the morning time detectability results, native species showed no significant difference in calling times before and after sunrise, while non-native species were detected primarily after sunrise. Native passerines in Mo'orean perhaps avoid competition with non-natives by calling before sunrise when there is less non-native activity and less obfuscation of native calls. This result agrees with the notion of non-native species displacing native species from their behavioral niches (Mooney \& Hobbs, 2000), in this case in terms of acoustic transmission.

Additional studies should be conducted to look into the morning calling times of native birds in areas where there are no non-native birds present, compared to areas with a loud non-native bird chorus to verify if natives are avoiding the non-native chorus. In addition, birds may be active in calling at dusk as well as dawn (Zwart et al., 2014). Calling patterns prior to dusk should be investigated to see if there is a different calling pattern for non-native and natives in the late afternoon.

\section{Ecology of non-native and native avifauna}

The results of the present study demonstrate that non-native bird species thrive in all of the tested habitats consistent with prior studies showing non-natives prospering in disrupted habitats (Mack et al., 2000; Gurevitch \& Padilla, 2004). The non-native common myna was significantly more active in the habitats disrupted by agricultural expansion. Interestingly, common myna removal projects have been initiated in the forests of Mo'orea's neighbor island, Tahiti, to protect native species (BirdLife International, 2016). Common myna removal projects may prove to be more effective if conducted in agricultural areas as well as forests, based on our findings that common mynas were less frequently detected in forests.

There is very little information about the habitat requirements, calling activity, and natural history of native avifauna in French Polynesia (Coulombe et al., 2011). Mo'orean kingfishers were shown in this study to have low call counts, low detection probability, and a negative correlation with non-native calling activity in all of the habitats studied. Future research should 
378 analyze habitat preferences of Mo'orean kingfishers in greater detail. Closely related kingfisher

379 species have been seen habituating coconut trees in managed and unmanaged coconut farms

380 (Coulombe et al. 2001). Studies of the Mo'orean kingfisher should be conducted in coconut

381 farms to support or refute this idea.

382

383

384

385

386

387

388

389

390

391

392

393

394

395

396

397

398

399

400

401

402

403

404

405

406

407

408

409

410

411

412

413

414

415

416

417

418

419

420

421

422

423

Grey-green fruit dove exhibited low calling activity, lower occupancy than other species, and low detection probabilities in all habitats studied. Grey-green fruit doves were more active in mixed habitats with moderate canopy cover; however, the differences were insignificant. Different canopy cover and habitats should be analyzed to see what the preferential habitat is for grey-green fruit dove so population restoration can be put into action.

\section{Conclusion}

Multi-species occupancy modeling and automated acoustic recording devices are tools that could be used to increase the precision of parameter estimation for testing habitat and behavioral hypotheses. We applied them to provide the first comprehensive evaluation of avifauna on Mo'orea. Altogether our findings suggest that native species are avoiding calling when nonnatives are active and that abundances of natives may be substantially lower than of non-natives. Forest may provide a refuge for native species because non-natives were detected less frequently there. However, the conclusions of our study are limited by a small sample size. We recommend additional sampling using our methods as well as point counts. Additional surveys are necessary to create a clearer picture of the habitat preferences Mo'orean kingfishers and grey-green fruit doves and the interactions of these species with non-native avifauna. This information will be essential for planning conservation actions protecting native birds in French Polynesia from endangerment or extinction.

\section{Acknowledgements.}

We would like to thank Dr. Justin Brashares, Dr. Cindy Looy, Dr. Patrick O'Grady, and Dr. Johnathan Stillman from University of California, Berkeley for their invaluable advice and support throughout this research study. Also, Scripps Institution of Oceanography's Dr. John Hildebrand and University of California, Berkeley's Dr. Justin Brashares for supplying us with automated acoustic recording devices. Without their generosity, this study would not have been possible. Thank you to Eric Armstrong and Ignacio Escalante (University of California, Berkeley) for their assistance with statistical analyses. We would like to acknowledge Natalie Stauffer-Olsen (University or California, Berkeley) for her guidance in writing of the manuscript. Thanks to the Gump Station for providing housing and company. Special thanks to Eric Lehmer for his support with making the maps in this paper. Finally, thank you to the fellow undergraduate student researchers that inspired us every day.

\section{References.}

Baumann-Pickering S, Roch MA, Wiggins SM, Schnitzler HU, Hildebrand JA. 2015. Acoustic behavior of melon-headed whales varies on a diel cycle. Behav Ecol Sociobiol 69(9):1553-1563. DOI:10.1007/s00265-015-1967-0.

Bibby CJ, Burgess ND, Hill DA, Mustoe SH. 2000. Bird census techniques. Second edition. Oxford: Oxford Academic Press. 
424

425

426

427

428

429

430

431

432

433

434

435

436

437

438

439

440

441

442

443

444

445

446

447

448

449

450

451

452

453

454

455

456

457

458

459

460

461

462

463

464

465

466

467

468

BirdLife International. 2016. Pomarea nigra. Available at http://www.iucnredlist.org/details/22707178/0 (accessed 26 February 2017).

BirdLife International. 2017. Species factsheet: Todiramphus youngi. Available at http://www.birdlife.org (accessed 26 February 2017).

Bovis, E. 1980. Tahitian society before the arrival of the europeans. Laie, Hawaii: Institute for Polynesian Studies.

Brandes TS. 2008. Automated sound recording and analysis techniques for bird surveys and conservation. BirdLife International 18:S163-S173. DOI: 10.1017/S0959270908000415

Briggs F, Huang Y, Raich R, Eftaxias K, Lei Z, Cukierski W, Hadley SF, Hadley A, Betts M, Fern XZ, Irvine J, Neal L, Thomas A, Fodor G, Tsoumakas G, Ng HW. Nguyen TNT, Huttunen H, Ruusuvuori P, Manninen T, Diment A, Virtanen T, Marzat J, Defretin J, Callender D, Hurlburt C, Larrey K, Milakov M. 2013. The 9th annual MLSP competition: New methods for acoustic classification of multiple simultaneous bird species in a noisy environment. IEEE International Workshop on Machine Learning for Signal Processing, MLSP. 22-25. DOI: 10.1109/MLSP.2013.6661934.

Bunce RGH, Watkins JW, Smart SM, Scott WA, Cooper A, Wilson P. 1997. Ecological factors controlling biodiversity in the British countryside (ECOFACT) Modules $1 \& 2$. Institutute of Terrestrial Ecology 41.

Catchpole CK, Slater PJB. 2008. Bird song: biological themes and variations. Second edition. Cambridge: Cambridge University Press.

Clarke B, Murray J, Johnson MS. 1984. The extinction of endemic species by a program of biological control. Pacific Science 38(2): 97-104.

Coulombe G, Kesler D, Gouni A. 2011. Agricultural coconut forest as habitat for the critically endangered Tamotu kingfisher (Todiramphus Gambieri Gertrudae). The Auk 128:283292.

Didham RK, Tylianakis JM, Hutchison MA, Ewers RM, Gemmell NJ, Rosenzweig ML, Vitousek PM, Wilcove DS, Sala OE, Simberloff D, Slobodkin LB, Gurevitch J, Padilla DK, Ricciardi A, Clavero M, García-Berthou E, Mack RN, Byers JE, Fazey I, Parker IM, MacDougall AS, Turkington R, Davis MA, Seabloom EW, Foster BL, Tilman D, Corbin JD, D’Antonio CM, Petren K, Case TJ, Farnsworth EJ, Mack MC, Wootton JT, Caughley G, Simberloff D., Holle B von. 2005. Are invasive species the drivers of ecological change? Trends in ecology \& evolution 20:470-474. DOI: 10.1016/j.tree.2005.07.006.

Ferdon EN. 1981. Early Tahiti as the explorers saw it, 1767-1797. Tuscon, Arizona: University of Arizona Press.

Florens FBV, Baider C, Martin GMN, Strasberg D. 2012. Surviving 370 years of human impact: 
472

473

474

475

476

477

478

479

480

481

482

483

484

485

486

487

488

489

490

491

492

493

494

495

496

497

498

499

500

501

502

503

504

505

506

507

508

509

510

511

512

513

514

what remains of tree diversity and structure of the lowland wet forests of oceanic island Mauritius? Biodiversity and Conservation 21:2139-2167. DOI: 10.1007/s10531-0120304-4.

Frommolt KH, Bardeli R, Clausen M. 2008. Advantages and disadvantages of acoustic monitoring of birds - realistic scenarios for automated bioacoustics monitoring in a densely populated region. In Computational Bioacoustics for Assessing Biodiversity. Proc. Of the Internat. Expert Meeting on IT-based Detection of Bioacoustical Patterns. BfN-Skripten 235: 83-92.

Furnas BJ, Callas RL. 2015. Using automated recorders and occupancy models to monitor common forest birds across a large geographic region. The Journal of Wildlife Management 79:325-337. DOI: 10.1002/jwmg.821.

Galindo-González J, Guevara S, Sosa VJ. 2000. Bat- and bird-generated seed rains at isolated trees in pastures in a tropical rainforest. Conservation Biology 14:1693-1703. DOI: 10.1046/j.1523-1739.2000.99072.x.

Gelman A, Carlin JB, Stern HS, Rubin DB. 2004. Bayesian data analysis. Boca Raton, Florida: Chapman \& Hall.

Google Earth V 7.1.7.2602. March 25, 2016. Opunohu Valley, Mo’orea. 17³1.434’S $149^{\circ} 50.887^{\prime} W$. Eye alt 21795 ft. DigitalGlobe. http://www.earth.google.com. Mountain View, CA: Google Inc.

Gurevitch J, Padilla DK. 2004. Are invasive species a major cause of extinctions? Trends in Ecology \& Evolution 19:470-474. DOI: 10.1016/j.tree.2004.07.005.

Haselmayer J, Quinn JS. 2000. A comparison of point counts and sound recording as bird survey methods in amazonian Southeast Peru. The Condor 102:887-893. DOI: 10.1650/00105422(2000)102[0887:ACOPCA]2.0.CO;2.

Hobson KA, Rempel RS, Greenwood H, Turnbull B, van Wilgenburg SL. 2002. Acoustic surveys of birds using electronic recordings: New potential from an omnidirectional microphone system. Wildlife Society Bulletin 30:709-720. DOI: 10.2307/3784223.

Iknayan KJ, Tingley MW, Furnas BJ, Beissinger SR. 2014. Detecting diversity: emerging methods to estimate species diversity. Trends in Ecology \& Evolution 29:97-106.

Jones JM, Thayre BJ, Roth EH, Mahoney M, Sia I, Merculief K, Jackson C, Zeller C, Clare M, Bacon A, Weaver S, Gentes Z, Small RJ, Stirling I, Wiggins SM, Hildebrand JA. 2014. Ringed, bearded, and ribbon seal vocalizations north of Barrow, Alaska: Seasonal presence and relationship with sea ice. Arctic 67.2: 203.

Kellner K. 2015. Jags UI: a wrapper around rjags to streamling JAGS analyses. $R$ package version $1: 1$. 
515

516

517

518

519

520

521

522

523

524

525

526

527

528

529

530

531

532

533

534

535

536

537

538

539

540

541

542

543

544

545

546

547

548

549

550

551

552

553

554

555

556

557

558

559

560
Kennett DJ, Anderson A, Winterhalder B. 2006. The ideal free distribution, food production, and the colonization of Oceania. In Kennett DJ and Winterhalder B (ed.) Human Behavioral Ecology and the Origins of Food Production. University of California Press Berkeley. 265-288.

Langmore NE. 1998. Functions of Duet and Solo Songs of Female Birds. Trends in Ecology \& Evolution 13.4:136-40.

Lepofsky D, Kitch PV, Lertzman KP. 1996. Stratigraphic and Paleobotanical Evidence for Prehistoric Human-Induced Environmental Disturbance on Mo'orea French Polynesia. Pacific Science 50:253-273.

Mack RN, Simberloff D, Mark Lonsdale W, Evans H, Clout M, Bazzaz FA. 2000. Biotic invasions: Causes, epidemiology, global consequences, and control. Ecological Applications 10:689-710. DOI: 10.1890/1051-0761(2000)010[0689:BICEGC]2.0.CO;2.

MacKenzie DI, Nichols J, Royle J, Pollock K, Bailey L, Hines J. 2006. Occupancy estimation and modeling: inferring patterns and dynamics of species occurrence. Amsterdam: Elsevier Academic Press.

Marshall Cavendish Corporation. 2001. Endangered wildlife and plants of the world. Tarrytown, New York: Marshall Cavendish Corporation.

McCune CR, Grace JB, Urban DL. 2002. Analysis of ecological communities. Gleneden Beach, Oregon: MJM Software Design.

McGrann MC, Furnas BJ. 2016. Divergent species richness and vocal behavior in avian migratory guilds along an elevational gradient. Ecosphere 7:1419.

McKinney ML. 2002. Urbanization, biodiversity, and conservation. BioScience 52:883. DOI: 10.1641/0006-3568(2002)052[0883:UBAC]2.0.CO;2.

McLaughlin A, Mineau P. 1995. The impact of agricultural practices on biodiversity. Agriculture, Ecosystems \& Environment 55:201-212. DOI: 10.1016/01678809(95)00609-V.

Meyer JY, Butaud JF. 2009. Biological Invasions 11:1569. DOI:10.1007/s10530-008-9407-y.

Montgomerie RD, Weatherhead PJ. 1988. Risks and Rewards of Nest Defence by Parent Birds. The Quarterly Review of Biology 63.2:167-87.

Mooney HA, Hobbs RJ. 2000. Invasive species in a changing world. Washington, D.C: Island Press.

Paulay G. 1994. Biodiversity on oceanic islands: Its origin and extinction. American Zoologist 
561

562

563

564

565

566

567

568

569

570

571

572

573

574

575

576

577

578

579

580

581

582

583

584

585

586

587

588

589

590

591

592

593

594

595

596

597

598

599

600

601

602

603

604

605

606

$34: 134-144$.

Rempel RS, Hobson KA, Holborn G, van Wilgenburg SL, Elliott J. 2005. Bioacoustic monitoring of forest songbirds: interpreter variability and effects of configuration and digital processing methods in the laboratory. Source Journal of Field Ornithology Winter J. Field Ornithol 76:1-11. DOI: 10.1648/0273-8570-76.1.1.

Repetto R. 1988. The forest is for the trees? Government policies and the misuse of forest resources. Washington D.C.:World Resource Institute.

Royle JA, Nichols JD. 2003. Estimating abundance from repeated presence-absence data or point counts. Ecology 84:777-790.

Sakagawa B. 1993. Family Plot Agriculture on Moorea: Past, Present and Future. Biology and Geomorphology of Tropical Islands, University of California at Berkeley.

Scullion J, Ramshaw GA. 1987. Effects of various manurial treatments on earthworm activity in grassland. Biological Agriculture \& Horticulture 4:271-281. DOI: 10.1080/01448765.1987.9755113.

Sharma S. 1996. Applied multivariate techniques. John Wiley and Sons, New York, USA.

Spotswood EN. 2011. Interactions of avian frugivores and invasive trees in French Polynesia. Thesis, University of California, Berkeley.

Stoate C, Báldi A, Beja P, Boatman ND, Herzon I, van Doorn A, de Snoo GR, Rakosy L, Ramwell C. 2009. Ecological impacts of early 21st century agricultural change in Europe - A review. Journal of Environmental Management 91:22-46. DOI: 10.1016/j.jenvman.2009.07.005.

Tingley MW, Koo MS, Moritz C, Rush A, Beissinger SR. 2012. The push and pull of climate change causes heterogeneous shifts in avian elevational ranges. Global Change Biology 18:3279-3290.

Tucker GM. 1992. Effects of agricultural practices on field use by invertebrate-feeding birds in winter. The Journal of Applied Ecology 29:779. DOI: 10.2307/2404488.

Vickery JA, Tallowin JR, Feber RE, Asteraki EJ, Atkinson PW, Fuller RJ, Brown VK. 2001. The management of lowland neutral grasslands in Britain: effects of agricultural practices on birds and their food resources. Journal of Applied Ecology 38:647-664. DOI: 10.1046/j.13652664.2001.00626.x.

Whistler WA. 1991. Polynesian plant introductions. In: Cox PA, Banack SA, Brigham Young University, Hawaii Campus, ed. Institute for Polynesian Studies Islands, plants, and Polynesians: an introduction to Polynesian ethnobotany: proceedings of a symposium. Portland, Oregon: Dioscorides Press. 41-66. 
607 Wray A. 2013. Avian community structure: Land use impacts on beta diversity and species

608 richness in three distinct habitats on Mo'orea, French Polynesia. Biology and

609

610

611 Zwart MC, Baker A, Mcgowan PJK, Whittingham MJ. 2014. The Use of Automated Bioacoustic

612

613

Recorders to Replace Human Wildlife Surveys: An Example Using Nightjars. PLoS one 9.7 
Figure 1

Map of Mo'orea with sampling sites

Sampling sites in the Opunohu Valley of Mo'orea. Black squares indicate forest sites. Gray circles are mixed-covered sites. White triangles are agricultural sites.

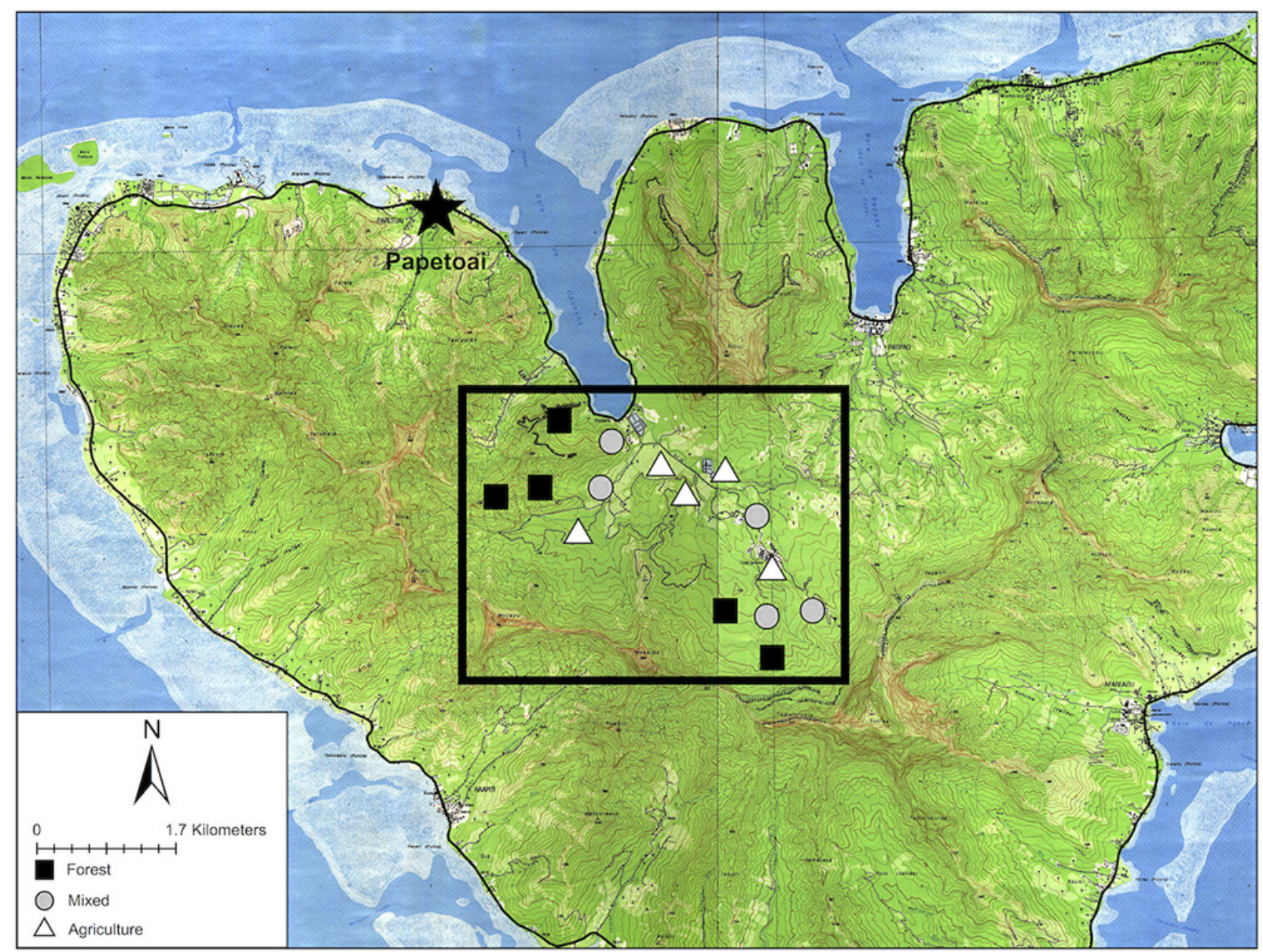


Figure 2

Map of Society Islands

Society islands including Tahiti, Mo'orea, Tetiaroa, Maiao, Huahini, Raiatea, Tahaa, Bora Bora, Tupai, Maupiti, Maupihaa, Manuae, and Motu One. The island sampled, Mo'orea, is marked by a red star.

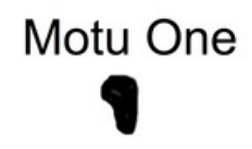

Manuae

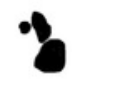

Maupihaa

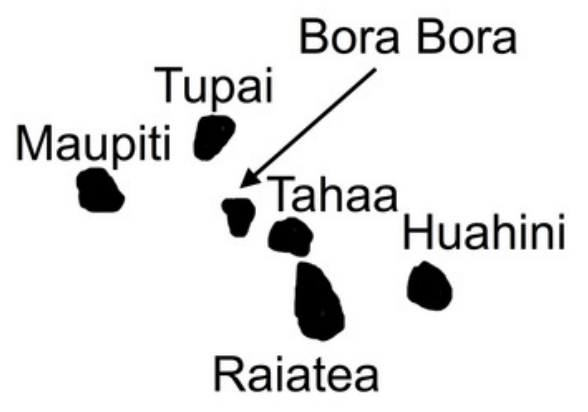

South

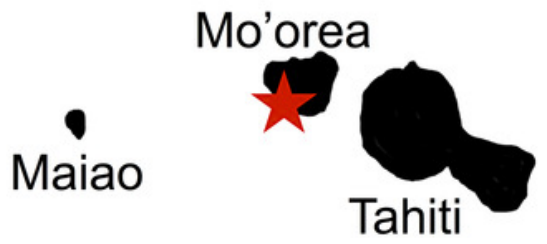

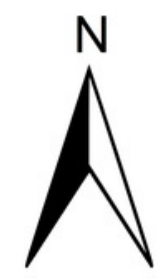

Pacific Ocean

Tetiaroa

$\bullet$

Tahiti

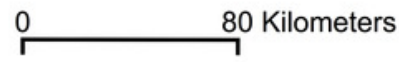




\section{Figure 3 (on next page)}

Hierarchical clustering of co-detection of nine bird species from five sites

Hierarchical clustering was limited to the five sites at which all nine bird species were

present. Temporal partitioning and vocal behavior of the nine birds are presented with this clustering. 


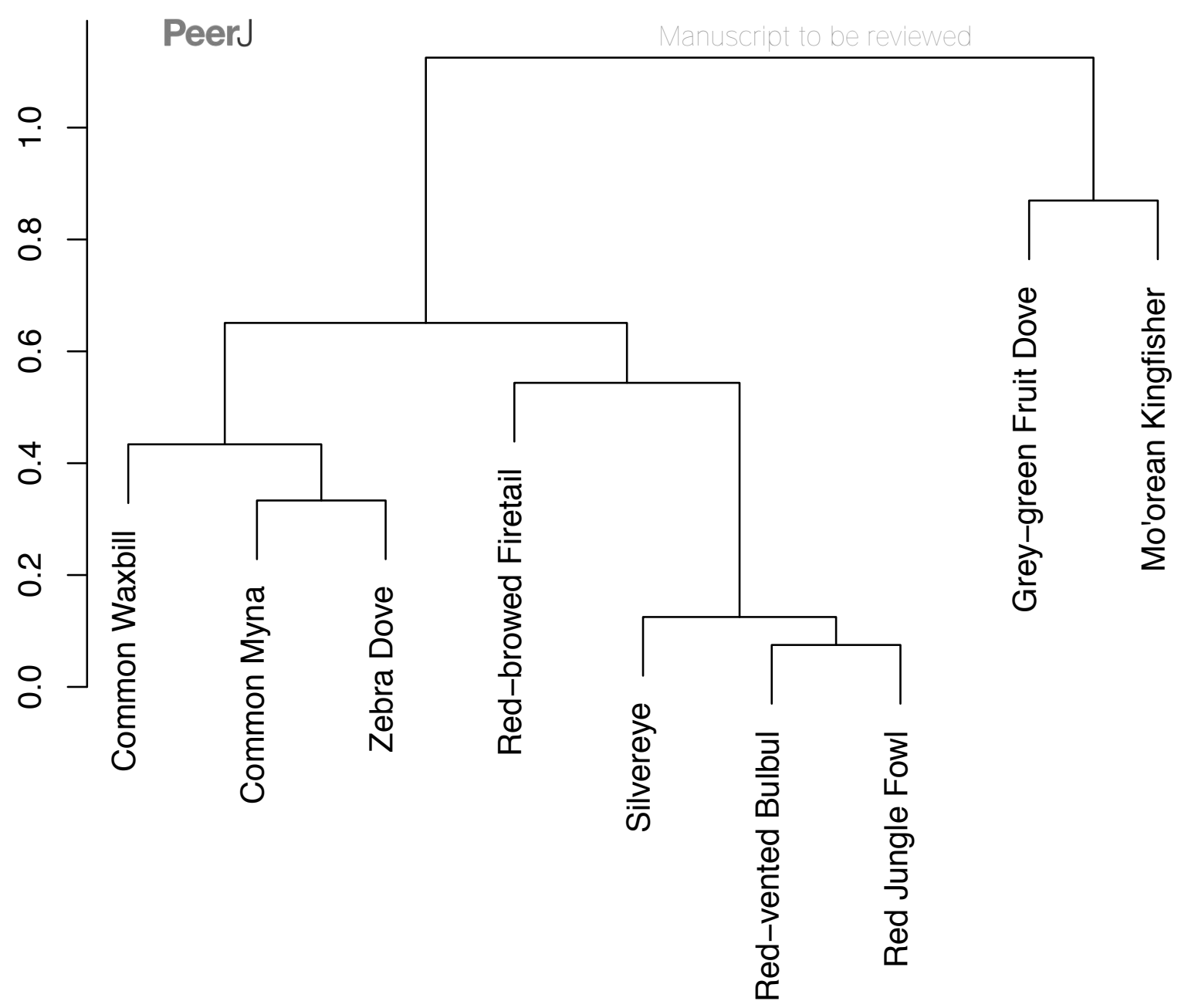

Species 


\section{Figure 4 (on next page)}

\section{Estimated occupancy}

Estimated occupancies of avian species surveyed using automated recorders. A multispecies occupancy model was used to address potential bias due to detection probabilities $<1$. Naive occupancy is the proportion of survey sites at which a species was detected. 


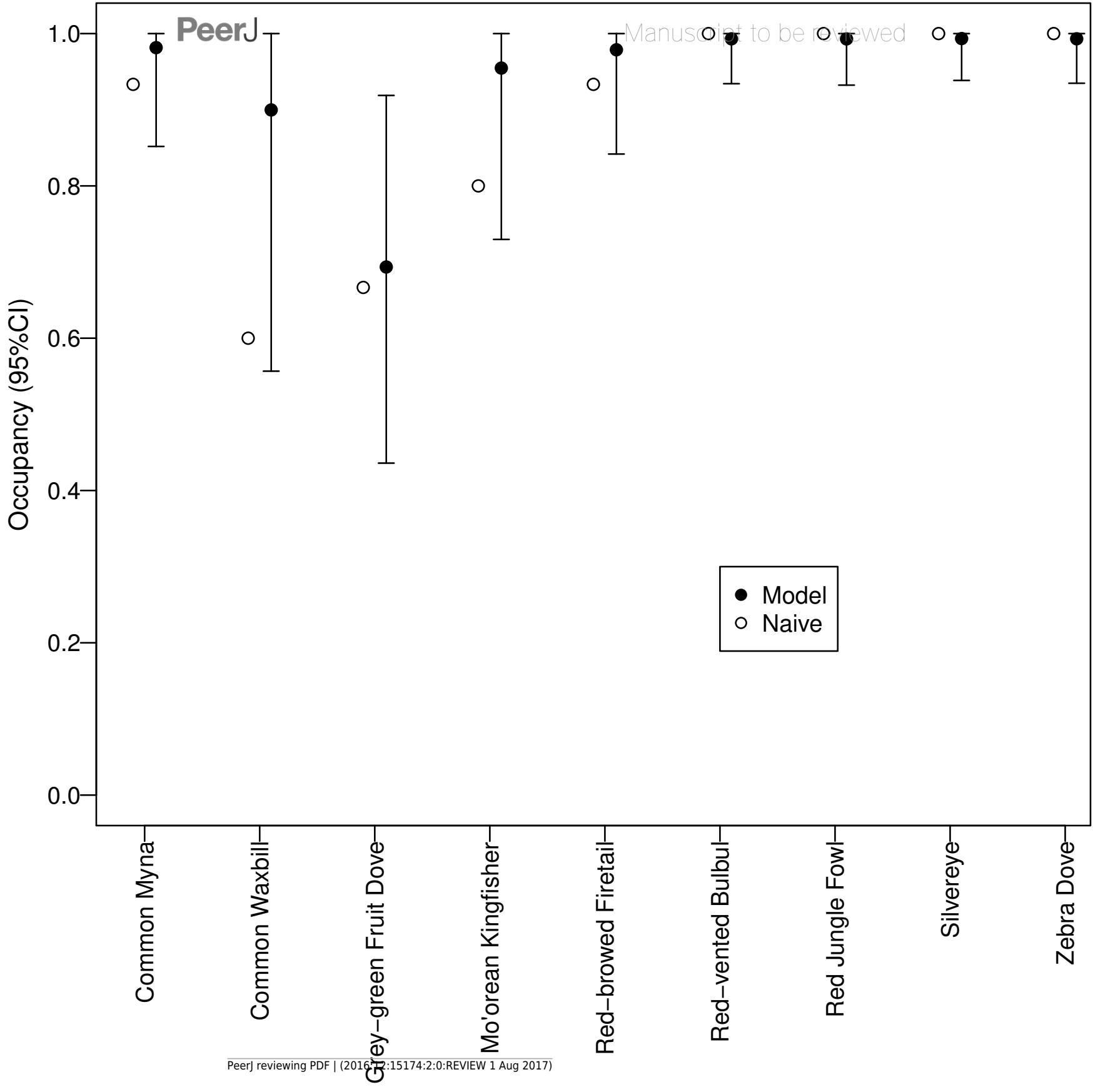


Figure $\mathbf{5}$ (on next page)

Canopy cover detection probability

Associations between forest canopy cover and detection probability for avian species surveyed using automated recorders. We deemed there to be an association when the credible interval for the parameter estimate did not overlap zero. 


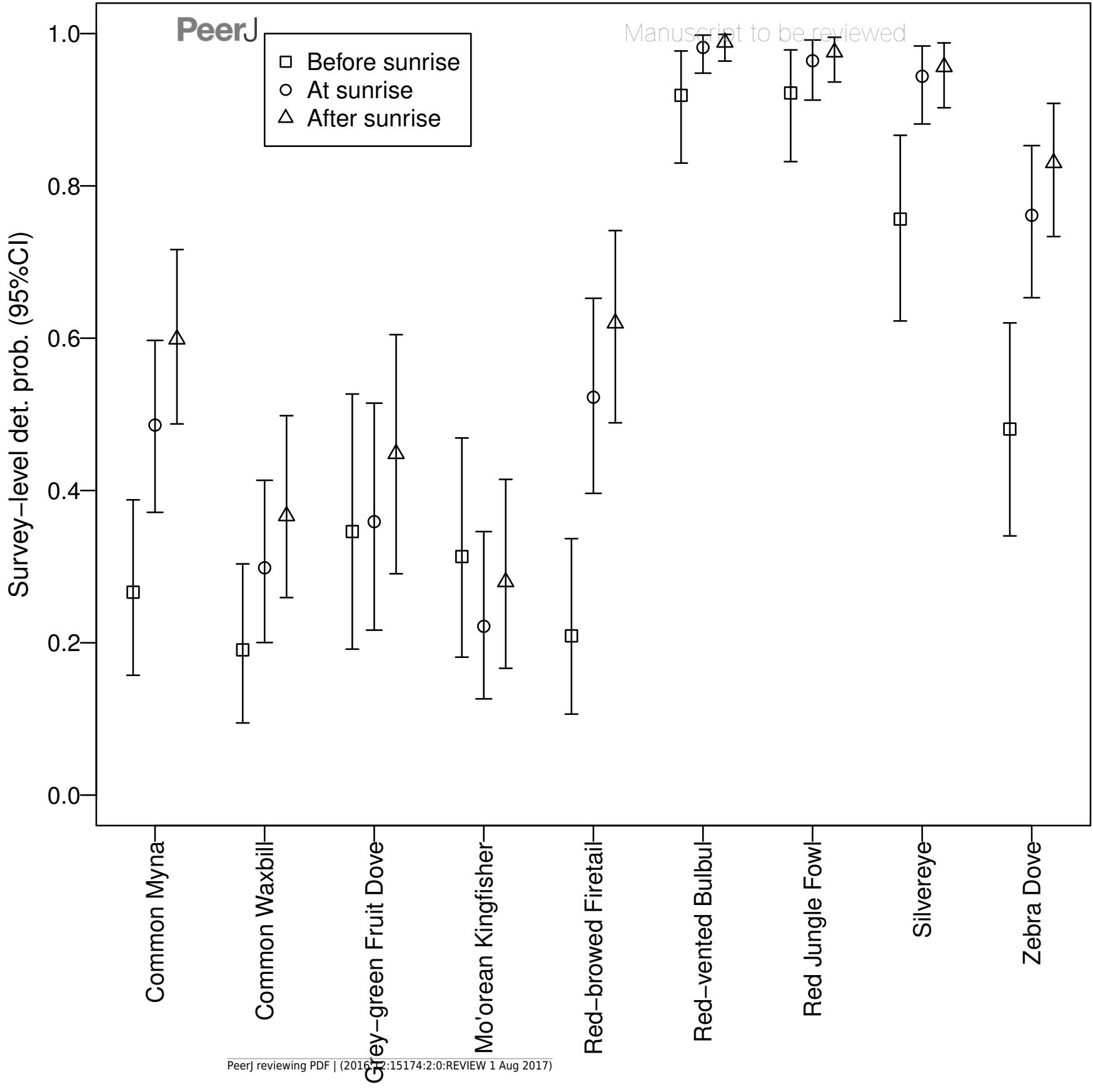




\section{Figure 6 (on next page)}

\section{Estimated detection probabilities}

Estimated detection probabilities of of avian species surveyed using automated recorders. Surveys were 5 minutes once a day repeated over 3 consecutive days commencing 30 minutes before sunrise, at sunrise, and 30 minutes after sunrise. 


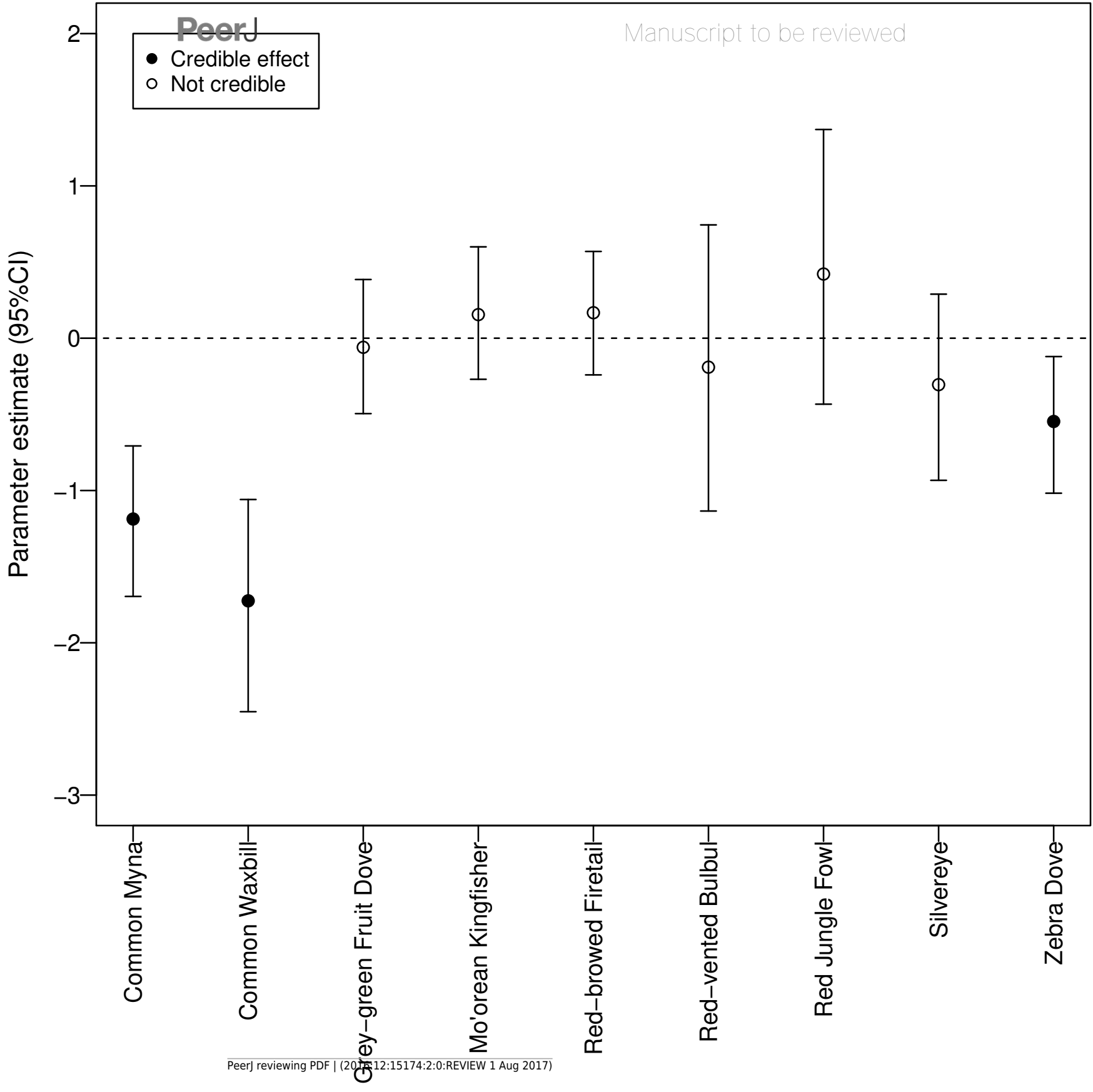




\section{Table $\mathbf{1}$ (on next page)}

The effect of habitat association on number of calls

Mean call number for all three habitats including the standard error (SE). F-value, and P-value for all habitats. For all species, df total was 103, df factors was 2, and df error was 101. 


\begin{tabular}{|c|c|c|c|c|c|c|c|}
\hline & $\begin{array}{c}\text { Mean Call Number Agriculture } \pm \text { SE } \\
\text { (\# Calls) }\end{array}$ & $\begin{array}{c}\text { Mean Call Number Forest } \pm \text { SE } \\
\text { (\# Calls) }\end{array}$ & $\begin{array}{c}\text { Mean Call Number Mixed } \pm \text { SE } \\
\text { (\# Calls) }\end{array}$ & F-value & $\begin{array}{c}\text { Agriculture-Forest } \\
\text { P-value }\end{array}$ & $\begin{array}{l}\text { Agriculture-Mixed } \\
\text { P-value }\end{array}$ & $\begin{array}{c}\text { Forest-Mixed } \\
\text { P-value }\end{array}$ \\
\hline Red-vented Bulbul & $202.30 \pm 28.98$ & $141.78 \pm 19.76$ & $101.58+12.99$ & 5.21 & 0.13 & 0.01 & 0.42 \\
\hline Red Jungle Fowl & $34.14 \pm 4.76$ & $51.92 \pm 6.45$ & $29.33 \pm 4.51$ & 4.93 & 0.05 & 0.80 & 0.01 \\
\hline Zebra Dove & $44.73 \pm 7.81$ & $4.58 \pm 1.41$ & $21.45 \pm 5.07$ & 13.79 & 0.00 & 0.01 & 0.09 \\
\hline Common Myna & $20.57 \pm 4.25$ & $1.06 \pm 0.46$ & $3.00 \pm 1.58$ & 16.01 & 0.00 & 0.00 & 0.87 \\
\hline Silvereye & $272.62 \pm 37.07$ & $269.97 \pm 43.46$ & $175.82 \pm 27.63$ & 2.13 & 1.00 & 0.16 & 0.18 \\
\hline Common Waxbill & $41.05 \pm 11.72$ & $0.17 \pm 0.17$ & $0.52 \pm 0.25$ & 11.23 & 0.00 & 0.00 & 1.00 \\
\hline Red-browed Firetail & $1.97 \pm 0.68$ & $4.58 \pm 1.80$ & $5.21 \pm 1.87$ & 1.30 & 0.44 & 0.30 & 0.96 \\
\hline Mo'orean Kingfisher & $0.54 \pm 0.19$ & $0.58 \pm 0.22$ & $0.48 \pm 0.32$ & 0.04 & 0.99 & 0.99 & 0.96 \\
\hline Grey-green Fruit Dove & $0.27 \pm 0.11$ & $0.44 \pm 0.12$ & $0.48 \pm 0.15$ & 0.85 & 0.58 & 0.45 & 0.97 \\
\hline
\end{tabular}

